\title{
Cobertura y niveles de intervención de los manglares del Pacífico chocoano
}

\section{Cover and levels of intervention of the mangrove swamps of Pacifico Chocoano}

\author{
William Klinger Brahan, Ing Forest, MSc*

\section{RESUMEN}

Los manglares son un grupo de ecosistemas en los que agua, fondo y raíces sirven de soporte a diversas comunidades con diferentes grados de tolerancia a la salinidad. Para determinar la superficie cubierta por este tipo de ecosistemas en los municipios que conforman la costa Pacífica chocoana (Juradó, Bahía Solano, Nuquí, Bajo Baudó y Litoral del San Juan) y establecer los niveles de intervención de los mismos, se utilizaron imágenes de satélite que se corroboraron con trabajo de campo, también dirigido al conocimiento de los grados de intervención que sufre el ecosistema mediante el establecimiento de una calificación de acuerdo con el porcentaje de área afectada. Se encontró que la mayor cobertura de manglares en la costa Pacífica chocoana se encuentra en los municipios del Bajo Baudó y Litoral del San Juan (85\%) y que el estado de conservación de los natales es cercano a 73\%, aunque en Bahía Solano se presentan altos grados de intervención (100\%). Se concluyó que en nueve años transcurridos entre 1997 y 2005, el Pacífico chocoano sufrió una pérdida de $36 \%$ de su ecosistema de manglar, que equivale a la desaparición 2603.8 ha/año, lo que denota la necesidad de establecer medidas de control que permitan detener el avance del daño.

Palabras clave: Manglar; Natal; Superficie; Cobertura; Intervención.

\section{ABSTRACT}

The mangrove swamps are a group of ecosystems in which water, bottom and roots serve of community support diverse with different degrees of tolerance from the salinity. Because for to determine the surface covered by this type of ecosystems in the municipalities that conform the chocoana pacific coast (Juradó, Bahía Solano, Nuquí, Bajo Baudó and Litoral del San Juan) and to establish the levels of intervention of the same, satellite imageries were used that were corroborated with work of field, also directed to the knowledge of the intervention degrees that undergo the ecosystem by means of the establishment of a qualification according to the percentage of affected area. It find was that the greater cover of mangrove swamps in the chocoana pacific coast is in the municipalities of the Bajo Baudo and Litoral del San Juan (85\%) and that the state of conservation of the birthdays is near 73\%, although in Bahia Solano stops appear intervention degrees (100\%). Which concluded that in 9 years passed between 1997 and 2005, the chocoano Pacific has suffered a loss of $36 \%$ of its ecosystem of mangrove swamp, is equivalent to the 2603.8 disappearance Ha/año, which denotes the necessity to establish control measures which they allow to delay the advance of the damage.

Keywords: Mangrove swamp; Natal; Surface; Cover; Intervention.

\author{
Profesor Titular, Universidad Distrital \\ Francisco José de Caldas, Facultad de Me- \\ dio Ambiente y Recursos Naturales, Grupo \\ de Investigación PROPOBOS y Director \\ del Instituto de Investigaciones Ambienta- \\ les del Pacífico, Quibdó, Colombia. \\ e-mail: williamklingerbraham@hotmail.com
}

Recibido: 24 de septiembre, 2010

Aceptado: 14 de octubre, 2010 


\section{INTRODUCCIÓN}

Los manglares son ecosistemas de reconocida importancia estratégica por su función ecológica y por sus niveles de producción. Desde el año 2002, mediante el mecanismo de cooperación horizontal, el Instituto de Investigaciones Ambientales del Pacífico (IIAP) con recursos de la Corporación Autónoma para el Desarrollo Sostenible del Chocó (CODECHOCO), adelantó la investigación titulada «Superficie del bosque de manglar del departamento del Chocó y estimación de tipos forestales de cobertura», información que se utiliza como base para la elaboración de este artículo.

Según Chapman (1984), con el término manglar se describe un grupo ecológico de especies halofíticas que pertenecen a diferentes familias, pero también a todo un grupo de ecosistemas en el que agua, fondo y raíces sirven de soporte a diversas comunidades con diferentes grados de tolerancia a la salinidad. Los manglares son bosques de pantanos, que se caracterizan por estar ubicados en litorales de suelo plano y fangoso, y aguas relativamente tranquilas (Sánchezy Álvarez 1997).

El trabajo se realizó con información de imágenes de satélite para determinar superficies de cobertura de manglar, que se corroboró con un intenso trabajo de campo, también dirigido al conocimiento de los grados de intervención que sufre el ecosistema. El departamento del Chocó, en lo correspondiente a su zona costera del océano Pacífico, está conformado por cinco municipios, todos ellos en mayor o menor grado con bosques de manglares, importante ecosistema estratégico reconocido en el mundo por su productividad y por su papel ecológico.

De norte a sur, en jurisdicción del departamento del Chocó, desde la frontera con Panamá hasta los límites con el departamento del Valle, se encuentran las siguientes municipalidades: Juradó, Bahía Solano, Nuquí, Bajo Baudó y Litoral del San Juan. Los habitantes de estos municipios históricamente han derivado parte de su sustento del manglar, lo que genera cierto grado de intervención sobre estos ecosistemas, $\mathrm{y}$ hace importante su conocimiento para orientar su manejo de manera adecuada.

El objetivo del artículo es determinar la superficie cubierta por ecosistema de manglar en los municipios que conforman la costa Pacífica chocoana, Juradó, Bahía Solano, Nuquí, Bajo Baudó y Litoral del San Juan, y establecer los niveles de intervención de los mismos.

\section{ÁREADEESTUDIO}

Este estudio abarca todas las áreas de manglar presentes en los municipios de la costa chocoana: Juradó, Bahía Solano, Nuquí, Bajo Baudó y Litoral del San Juan, cuyas características ambientales y biológicas son similares en algunos aspectos y particulares en otros. En la costa del Pacífico los manglares se presentan como una faja paralela al litoral, que en algunas partes penetra hacia el continente $20 \mathrm{~km}$ o más con influencia de la marea; esta faja va desde el sur en la frontera con Ecuador y se remonta hasta Cabo Corrientes, se sucede en algunas manchas hasta llegar a los límites con la República de Panamá. Las áreas de manglar se encuentran de norte a sur, en Juradó, en la encenada de Utría, reaparecen en Nuquí, hacia el sur de cabo Corrientes aparecen los manglares de VirudóCatripe, y los de la desembocadura del río Baudó y el río San Juan, y hacia el sur reaparecen en las bahías de Málaga y Buenaventura (Villalba 2008). Estos municipios, como la mayoría de los del Pacífico, poseen una de las precipitaciones más altas del planeta y las mareas oscilan en un rango de alrededor de cuatro metros, cuyas características producen, entre otros efectos, que los mangles del litoral Pacífico alcancen los $40 \mathrm{~m}$ de altura, donde las principales especies son Pelliciera rhizophorae y Mora megistosperma en áreas extensas denominadas natales (Phral et al. 1990). En cuanto a la fauna, en esta área del Pacífico sobre los troncos bañados por las mareas, se incrustan algas que son alimento de moluscos durante la marea baja al igual que el cangrejo tasquero Goniopsis cruentata. En las raíces se encuentran la ostra Crassostrea rhizophorae que es el habitante típico, y el caracol Thais kiosquiformis que preda las ostras y los cirripeditos Balanus sp.; también se destacan otras especies como Teredo novilis, Ophiotrix, Anadara spp., Penaeus spp., Alpheus spp., Xiphopenaeus kroyeri y Anamalocardia sp. entre otras. Asimismo, se encuentran especies ícticas asociadas con el manglar como róbalo, mojarra, lebrance, lisa, sábalo, barbudo, pargo, barracuda y corbinata, entre otras (Sánchez etal. 2004).

\section{MÉTODOS}

La metodología se dividió en dos partes, la primera de análisis de las imágenes digitales para establecer las coberturas del ecosistema y el trabajo de campo concerniente a la validación y verificación del estado del manglar de la zona de estudio.

Análisis de las imágenes digitales para manglar, la delineación y actualización de la línea costera. Se utilizaron imágenes de satélite corroboradas en campo para la fácil ubicación del ecosistema de manglar y conocer el estado actual del deterioro. Se utilizaron ocho imágenes multiespectrales de diferentes fechas de toma del satélite LANDSAT TM y ETM+, que abarcan la zona costera del Pacífico del departamento del Chocó; aunque para la generación de polígonos se procesaron sólo cuatro imágenes de las fechas más recientes $(2001,2000,1999$ y 1997), una imagen Radarsat y cartografía base de planchas IGAC. Para manejar la información digital de las imágenes y ligarlas al sistema coordenado 


\section{Bioetnia Volumen 7 No 2 (julio-diciembre), 2010}

IGAC se deben corregir los errores por geometría de la imagen, en especial Radar; se dispuso a geo-rectificar las imágenes mediante el empleo de la cartografía digital disponible de la zona del Pacífico a escala 1:25.000, como imágenes mosaico de la NASA con resolución de $15 \mathrm{~m}$ y en especial puntos de control tomados con la unidad de GPS Garmin en sitios claves que no estuvieran sujetos a dinamismo temporal.

Fase de campo. En esta etapa se realizaron dos visitas de campo; la primera se llevó a cabo en la zona costera de los municipios de Jurado, Bahía solano y Nuquí, y la segunda en los municipios de Bajo Baudó y Litoral de San Juan. Las visitas fueron esenciales para identificar los hábitats de manglar presentes en el área de estudio, registrar su localización, reconocer las otras coberturas vegetales que comparten la misma unidad paisajística y de relieve, y tomar puntos de control para rectificar las imágenes de satélite. Estos aspectos fueron muy útiles en el momento de realizar la clasificación de las imágenes satelitales, permitiendo obtener referencias independientes de datos que ayudaron a evaluar la precisión de los resultados alcanzados después del procesamiento digital de las imágenes satelitales.

Las visitas realizadas tuvieron el objetivo de hacer chequeos de comprobación en las parcelas de muestreo, realizadas en meses anteriores por el equipo. Además, fue de suma importancia la recolección de información para calibrar las imágenes satelitales, que cubren el área de estudio.

Grado de intervención del ecosistema. En este trabajo los niveles de intervención del ecosistema de manglar se calificaron en función del porcentaje de superficie intervenida. Se establecieron las siguientes calificaciones: para una superficie intervenida entre $40 \%$ y $60 \%$ el grado de intervención es altamente intervenido, entre $20 \%$ y $40 \%$ medianamente intervenido y entre $0 \%$ y $20 \%$ la calificación será ecosistema poco intervenido.

En el manglar altamente intervenido predominan árboles con alturas que oscilan entre los 5 y 12 metros, en los medianamente intervenidos los árboles alcanzan entre 12 y 25 metros de altura, mientras que en los manglares poco intervenidos se encuentran árboles con alturas que van desde 25 hasta 35 metros.

El ecosistema de manglar se encuentra acompañado de manchas relativamente homogéneas de la especie Nato (Mora megistosperma), los datos que se suministran en este documento separan la información del nato y mangles, pero en la consolidación de superficies se las adiciona para un mayor entendimiento del lector.

En el siguiente contenido se describe la situación de los manglares existentes en cada uno de los municipios que conforman la costa Pacífica chocoana, se enfatiza en la superficie total que cubren los manglares, tomando la superficie cubierta por el Nato como parte del ecosistema de manglar, pero también se hace un análisis por separado de las áreas cubiertas por especies de mangles y de las áreas cubiertas por el Nato.

\section{RESULTADOSYDISCUSIÓN}

Cobertura y niveles de intervención de los manglares en el municipio de Nuquí. El municipio de Nuquí cuenta con una importante franja de manglar casi ininterrumpida que va desde el corregimiento de Juribidá en el norte hasta el corregimiento de Panguí en el sur, pasando por la superficie más significativa en el corregimiento de Tribugá. Esta franja es ligeramente cortada frente al morro San Francisco y en los alrededores de la pista de aterrizaje ubicada en pleno casco urbano de su cabecera municipal. Un poco más al sur virando hacia occidente, hay otra importante mancha aislada de manglar en el corregimiento de Coquí, que se encuentra fuertemente influida por la presencia del río que lleva el mismo nombre y por las quebradas Besuquillo, Trapiche, Trapichito, Los Chingos y Barbodera, para encontrar luego, de manera significativa más al occidente, manchas casi incipientes de manglar en el corregimiento de Jobí y un poco más pronunciada en el corregimiento de Arusí.

Nuquí tiene en total 3002.4 hectáreas en ecosistema de manglar, pero lastimosamente más de $59 \%$ de esta superficie se encuentra en altos niveles de intervención, lo que muestra el inminente peligro en el que se encuentra este ecosistema en la jurisdicción del municipio; los sitios donde más se presenta esta situación son Arusí, Jobí, Panguí y Juribidá, lugares en donde prácticamente no existe otra categoría de intervención. Otro $16.8 \%$ de la superficie de manglares del municipio de Nuquí presenta niveles medios de intervención, situación que ubica a la municipalidad con más de $75 \%$ de sus manglares en inadecuado estado de conservación. Esta categoría de intervención predomina en Nuquí, Tribugá y Chorí.

El municipio cuenta con 716.4 hectáreas en bosque de mangles y Natos poco intervenidos que se podrían convertir en el elemento central de un programa de trabajo orientado a la recuperación de otras áreas más intervenidas. Los manglares poco intervenidos están ubicados exclusivamente desde Tribugá hacia el norte hasta llegar al estero El Piñal. En el Figura 1 se presenta la cobertura de bosque de manglar correspondiente al municipio de Nuquí, destacándose con color rojo las áreas cubiertas por este importante ecosistema. En la Tabla 1 se resume la situación de intervención que presentan los manglares del municipio de Nuquí.

Si se comparan los manglares propiamente dichos con los natales, estos últimos presentan un mejor estado de conservación, mientras los manglares sólo tienen $12.4 \%$ de superficie en condiciones de poca intervención; $80.4 \%$ de los natales se encuentran poco intervenidos, esta situación denota claramente un evento al que se debe prestar atención cuando se ponga en marcha cualquier programa orientado a mantener 
Tabla 1

Niveles de intervención de los manglares y natales en el municipio de Nuquí

\begin{tabular}{lrrrrrrrr}
\hline Grado de intervención & \multicolumn{2}{c}{ Manglar } & & \multicolumn{2}{c}{ Natal } & & \multicolumn{2}{c}{ Manglar y Natal } \\
\cline { 2 - 3 } & Ha & \% & & Ha & \% & & Ha & \% \\
\hline Altamente intervenido & 1.698 .8 & 67.7 & & 100.3 & 19.6 & & 1.799 .1 & 59.5 \\
Medianamente intervenido & 506.9 & 20.2 & & 0.0 & 0.0 & & 506.9 & 16.8 \\
Poco intervenido & 304.7 & 12.1 & & 411.7 & 80.4 & & 716.4 & 23.7 \\
Total & 2.510 .4 & 100.0 & & 512.0 & 100.0 & & 3.022 .4 & 100.0 \\
\hline
\end{tabular}

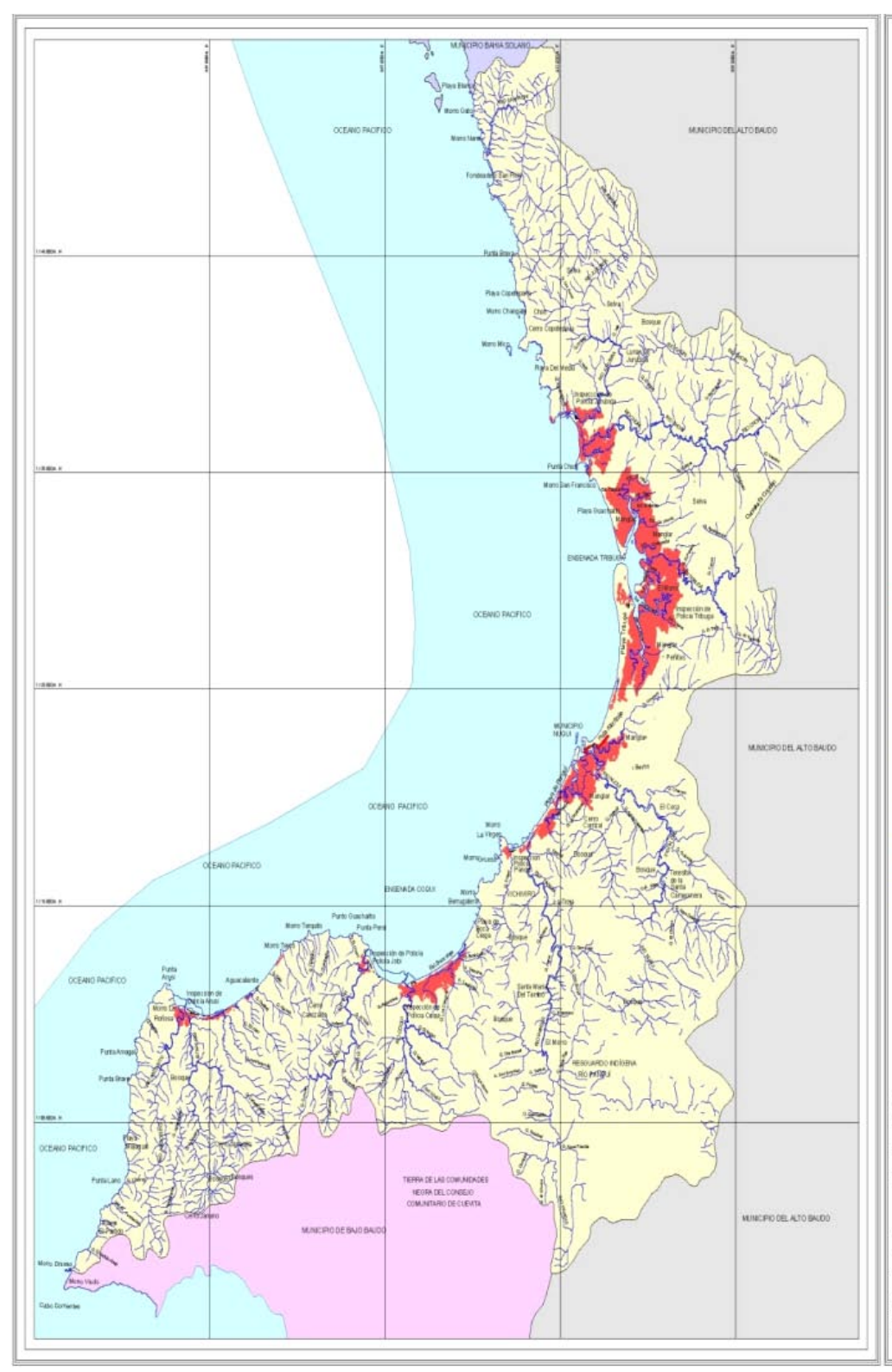

Figura 1. Unidades de cobertura del bosque de manglar Municipio de Nuquí. 


\section{Bioetnia Volumen 7 № 2 (julio-diciembre), 2010}

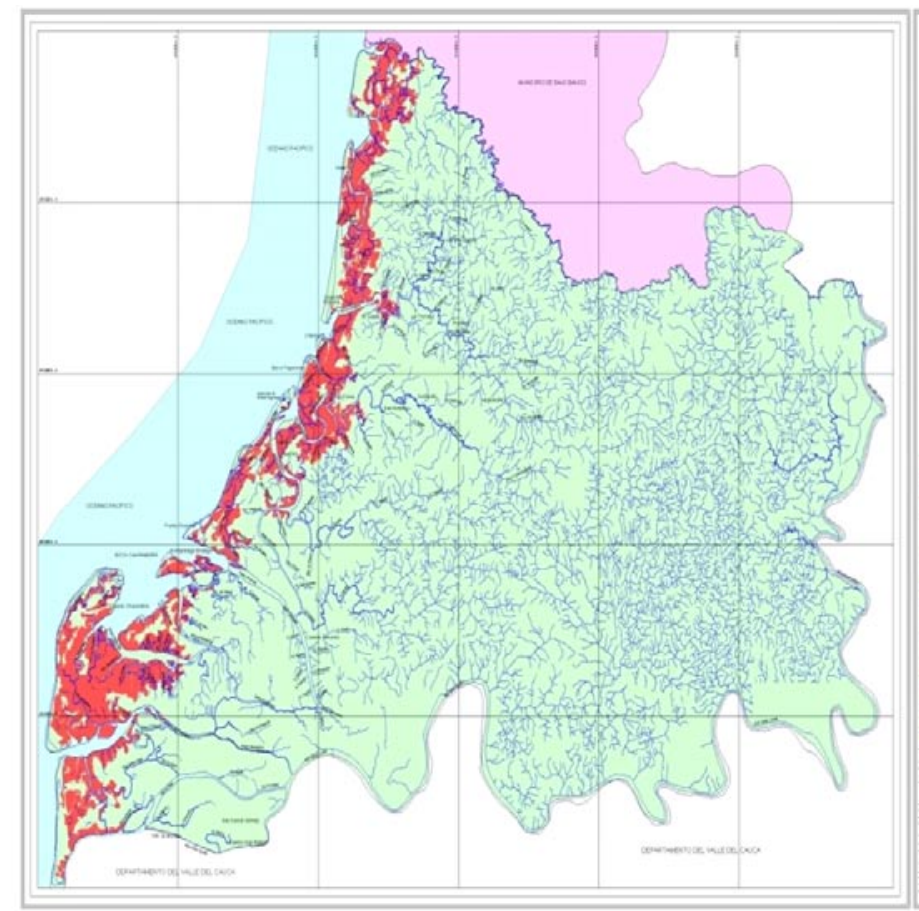

\section{Figura 2. Unidades de cobertura de manglar en el Litoral del San Juan.}

este ecosistema. Las manchas de natales conservados de manera adecuada se encuentran a lado y lado del río Arusicito, en cercanías de Coquí, en el estero El Muerto, en la quebrada La Esperanza y en el río Tribugá.

Cobertura y niveles de intervención de los manglares en el municipio Litoral delSan Juan. El municipio del Litoral del San Juan aporta al Pacífico chocoano una superficie de 11.063 hectáreas de manglares distribuidos de forma irregular de norte a sur por toda su costa, donde se destaca la presencia de manglar, como es de esperarse, hacia los ríos o brazos más importantes del municipio, Guarataco, Charambirá, Estebanico, Churimal, Docordó, Togoromá y Pichimá. Presenta niveles de intervención catalogados como altos, 5628.3 hectáreas de mangle, es decir, 50.9\% del total de la superficie ocupada por este ecosistema en el municipio del Litoral del San Juan hecho que enciende las alarmas sobre el manejo y protección que se debe dar a esta importante área del departamento del Chocó.

Los sitios que presentan mayor cercanía al río San Juan poseen altos grados de intervención, se destacan los esteros LaEquis, Tío Silirio y Madre Vieja. También en el extremo norte del Litoral del San Juan, se presentan grandes áreas con altos niveles de intervención, en cercanías del caserío La Víbora y el estero el Chupadero. En la Figura 2 se muestra la ubicación precisa de los ecosistemas de manglar que presenta el municipio de Litoral del San Juan y se ha distinguido con color rojo la presencia de este tipo de vegetación.

De otra parte, $23.1 \%$ de los manglares presentan un grado medio de intervención, lo que corresponde a 2558.2 hectáreas, que si se adicionan al otro 50.9\% altamente intervenido, deja claro que más de $73 \%$ de la superficie de manglar del municipio requiere de manera urgente el desarrollo de acciones dirigidas a garantizar su permanencia. Los manglares medianamente intervenidos se encuentran sobre todo hacia el sur y centro del municipio, entre los brazos Estebanico y Guarataco y entre los ríos Togoromá y Pichimá. Entre natales y manglares le quedan al municipio del Litoral del San Juan, tan sólo 2875.4 hectáreas en buen estado de conservación, es decir, con niveles de intervención bajos.

Tres manchas importantes de manglares bien conservados se visualizan en una mirada general de la cartografía levantada durante el desarrollo del trabajo, una en el sur de municipio, junto a los esteros el Bujío, San Antonio y Segura, conformada en su mayoría por mangles que alcanzan alturas de hasta 35 metros, otra al centro donde se encuentran en proporción muy similar manglares en los esteros El Sande y El Secadero, y natales en los esteros Peñita y El Camino en cercanías al río Togoromá, y por último, una mancha importante de Nato al oriente del río Pichimá en las quebradas El Tamboral y El Charco, y hacia el norte del caserío Pichimá. Mientras que la superficie de manglares bien conservados en el municipio del Litoral del San Juan es de tan sólo 11.5\%, el porcentaje de natales bien conservados va más allá de $69 \%$; esta situación muestra con claridad una tendencia que marca la preferencia por las especies de mangle propiamente dichas. En la Tabla 2 se resumen los datos relacionados con la vegetación de manglar en el municipio del Litoral del San Juan, 
Tabla 2

Niveles de intervención de los manglares y natales en el municipio de Litoral del San Juan

\begin{tabular}{lrrrrrrrr}
\hline \multirow{2}{*}{ Grado de intervención } & \multicolumn{2}{c}{ Manglar } & & \multicolumn{2}{c}{ Natal } & & \multicolumn{2}{c}{ Manglar y Natal } \\
\cline { 2 - 3 } & Ha & \% & & Ha & \% & & Ha & \% \\
\hline Altamente intervenido & 4.801 .9 & 57.7 & & 826.4 & 30.1 & & 5.628 .3 & 50.9 \\
Mediamente intervenido & 2.558 .2 & 30.8 & & 0.0 & 0.0 & & 2.558 .2 & 23.1 \\
Poco intervenido & 955.0 & 11.5 & 1.921 .5 & 69.9 & & 2.876 .5 & 26.0 \\
Total & 8.315 .1 & 100.0 & & 2.747 .9 & 100.0 & & 11.063 & 100.0 \\
\hline
\end{tabular}

información de gran utilidad para la toma de decisiones por parte de la autoridad ambiental del departamento. En la Figura 3 se presentan los tipos de cobertura de manglar en el municipio del Litoral del San Juan; se distinguen con diferentes colores los niveles de intervención de este ecosistema.

Cobertura y niveles de intervención de los manglares en el municipio Bahía Solano. En materia de superficie de cobertura de manglar, el municipio de Bahía Solano, entre los de la costa Pacífica chocoana, es el que menos aporta a la cobertura total de manglares en el departamento del Chocó, pues la presencia de este ecosistema se restringe sólo a 1070 hectáreas con grados de intervención tan altos que ameritan el trabajo mancomunado de diferentes instituciones en procura de acciones que de inmediato reviertan una situación que no sólo resulta preocupante, sino vergonzosa para un departamento que como el Chocó se ha jactado de tener una cultura de conservación.

La mancha integrada más grande de manglar se encuentra sobre el extremo norte del municipio en cercanías al corregimiento de Cupica, en límites con el municipio de Juradó. Dada la corta distancia entre la población y el ecosistema, éste se ha sometido a fuerte presión antrópica arrojando como resultado que la mayor parte de él presenta altos y medianos niveles de intervención. Otras manchas prácticamente incipientes se encuentran en Punta Nabugá, Playa Cocalito y Playa Brava hacia la parte

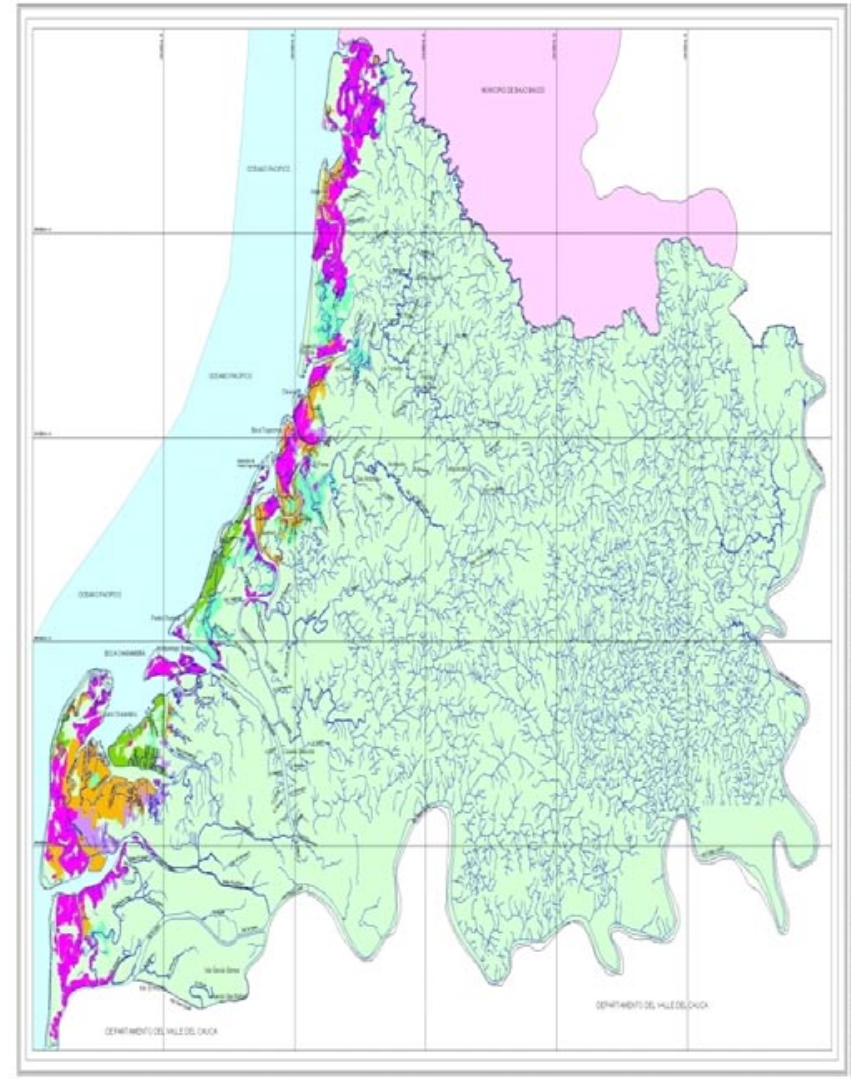

\section{Figura 3. Tipos forestales de de cobertura de manglar municipio de Litoral del San Juan.}

central del municipio, y más hacia el sur en la inspección de policía de Huaca, y las quebradas Juná y el Chorro, bastante al sur del municipio. Extensiones un poco más amplias que las anteriores se encuentran en Mecana, en el casco urbano de Bahía Solano, en el corregimiento del Valle, en el río Boroboro y en la Ensenada de Utría.

Tomando en cuenta de manera exclusiva la vegetación de manglares propiamente dicha, el municipio de Bahía Solano tiene 837.7 hectáreas, de las cuales 653.1 hectáreas presentan altos niveles de intervención; este dato corresponde a 77.9\% de la superficie total en manglares y se presenta en algunos lugares de Cupica, la Ensenada de Utría, el Valle, Bahía Solano, Mecana y Huaca, entre otros. De igual 


\section{Bioetnia Volumen 7 No 2 (julio-diciembre), 2010}

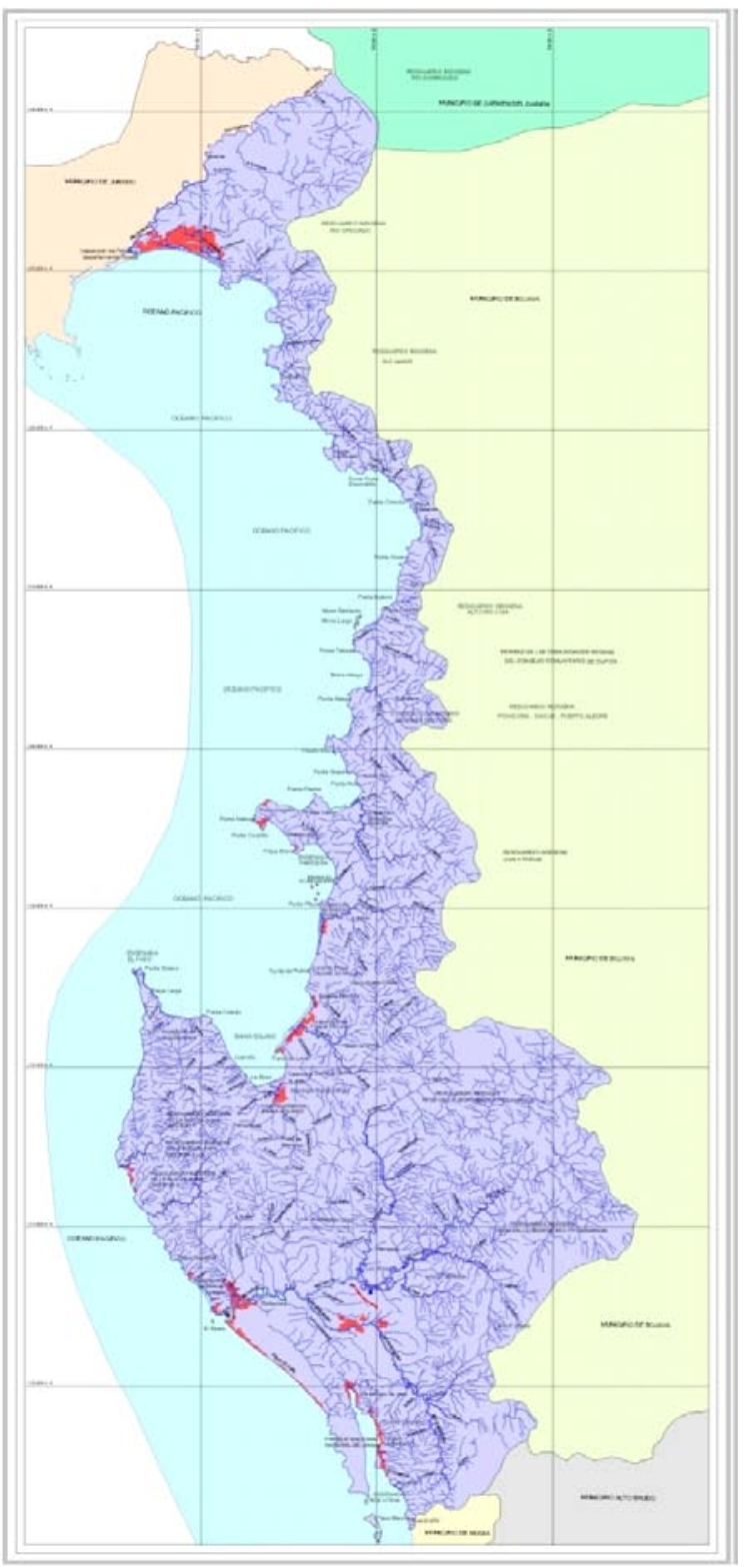

Figura 4. Unidades de cobertura de manglar en Bahía Solano.

manera, 99.5 hectáreas presentan medianos niveles de intervención, lo que corresponde a un $11.9 \%$ del total. Significa lo anterior, que cerca de $90 \%$ del manglar que se encuentra en jurisdicción del municipio ha sufrido los rigores de la intervención, lo que obliga a una pronta acción interinstitucional para detener su destrucción definitiva. Los sitios con mediano nivel de intervención se encuentran en Nabugá y Cupica.

El municipio cuenta sólo con $10 \%$ de sus manglares en buen estado de conservación, es decir, con un bajo grado de intervención; estos manglares se ubican exclusivamente en el corregimiento de Cupica, razón suficiente para prestar especial atención a este espacio geográfico. La Figura 4 muestra la manera como se distribuye el ecosistema de manglar en el municipio de Bahía Solano, distinguiendo con color rojo las manchas de esta vegetación.
Si se centra el análisis en la vegetación de Nato (Mora megistosperma) la situación es notoriamente peor, porque $100 \%$ del natal existente en el municipio presenta altos niveles de intervención, lo que conduce a pensar que habrá que manejar con mucho cuidado y adecuada intención la vegetación remanente para evitar que el municipio pierda la especie. Si se realiza un análisis que integre el natal y el manglar propiamente dicho, es evidente que $82.8 \%$ del total presenta altos niveles de intervención, $9.3 \%$ presenta medianos niveles de intervención y sólo $7.9 \%$ presenta bajos niveles de intervención o se encuentra poco intervenido. En resumen, esto significa que se debe prohibir así sea de manera temporal, cualquier actividad de aprovechamiento de la especie y que las zonas alta y medianamente intervenidas se deben empezar a recuperar. La Tabla 3 muestra en detalle la situación de los manglares y natales del municipio de Bahía Solano.

Cobertura y niveles de intervención de los manglares en el municipio Juradó. El municipio de Juradó posee una gran mancha de manglarubicada al centro norte de la municipalidad entre Curiche y Partadó, manchas medianas en el estero Cacique y Punta Ardita, y manchas incipientes en Aguacate y Coredó y las quebradas El Coco y Guarín. En total, Juradó aporta 2237.1 hectáreas al ecosistema de manglar de la costa Pacífica chocoana, lo que corresponde apenas a $5.4 \%$.

La mayor parte de esta superficie se encuentra en niveles de intervención que van de alto a mediano, tal es el caso de los manglares ubicados en el Cacique, en los límites entre Juradó y Bahía Solano en cercanías al corregimiento de Cupica, en donde no hay ni rastros de manglares en buen estado de conservación. El total de superficie de los manglares de Juradó en esta situación es casi $75 \%$, lo que es claro indicativo de lo que sucede con el ecosistema de manglar dentro del municipio. Juradó aún posee $25 \%$ de su superficie de manglar en adecuado estado de conservación, lo que significa la existencia de 578.1 hectáreas con bajos niveles 
Tabla 3

Niveles de intervención de los manglares y natales en el municipio de Bahía Solano

\begin{tabular}{|c|c|c|c|c|c|c|}
\hline \multirow[t]{2}{*}{ Grado de intervención } & \multicolumn{2}{|c|}{ Manglar } & \multicolumn{2}{|c|}{ Natal } & \multicolumn{2}{|c|}{ Manglar y Natal } \\
\hline & $\mathrm{Ha}$ & $\%$ & $\mathrm{Ha}$ & $\%$ & Ha & $\%$ \\
\hline Altamente intervenido & 653.1 & 77.9 & 232.3 & 100.0 & 885.4 & 82.8 \\
\hline Mediamente intervenido & 99.5 & 11.9 & 0.0 & 0.0 & 99.5 & 9.3 \\
\hline Poco intervenido & 85.1 & 10.2 & 0.0 & 0.0 & 85.1 & 7.9 \\
\hline Total & 837.7 & 100.0 & 232.3 & 100.0 & 1.070 .0 & 100.0 \\
\hline
\end{tabular}

Tabla 4

Niveles de intervención de los manglares y natales en el municipio de Juradó

\begin{tabular}{|c|c|c|c|c|c|c|}
\hline \multirow[t]{2}{*}{ Grado de intervención } & \multicolumn{2}{|c|}{ Manglar } & \multicolumn{2}{|c|}{ Natal } & \multicolumn{2}{|c|}{ Manglar y Natal } \\
\hline & Ha & $\%$ & $\mathrm{Ha}$ & $\%$ & Ha & $\%$ \\
\hline Altamente intervenido & 1.056 .2 & 50.4 & 0.0 & 0.0 & 1.056 .2 & 47.2 \\
\hline Medianamente intervenido & 602.8 & 28.7 & 0.0 & 0.0 & 602.8 & 26.9 \\
\hline Poco intervenido & 438.1 & 20.9 & 140.0 & 100.0 & 578.1 & 25.8 \\
\hline Total & 2.097 .1 & 100.0 & 140.0 & 100.0 & 2.237 .1 & 100.0 \\
\hline
\end{tabular}

de intervención, al tiempo que representa la esperanza de recuperación de un ecosistema que brinda excelentes beneficios a la comunidad que lo habita. Estos manglares se ubican en cercanías al estero de Curiche y en Punta Ardita. En la Tabla 4 se presenta el resumen de datos correspondiente a las existencias y estado del ecosistema de manglar en Juradó, así como la situación del manglar propiamente dicho y el natal.

Se destaca que en el municipio de Juradó, la totalidad de los natales existentes, que cubren unas 140 hectáreas casi todas ubicadas al sur de la desembocadura del río Partadó, se encuentran poco intervenidos, es decir, en un buen estado de conservación. En manglares propiamente dichos queda un 20.9\% de superficie, alrededor de 438 hectáreas poco intervenidas. La Figura 5 muestra la cobertura de manglar que tiene el municipio de Juradó.

Cobertura y niveles de intervención de los manglares en el municipio Bajo Baudó. Con sus 23.923,4 hectáreas, el municipio del Bajo Baudó en la costa Pacífica chocoana, es el de mayor aporte al ecosistema de manglar subregional; esta superficie representa cerca de $58 \%$ de todos los manglares del Pacífico chocoano. Sin embargo, el estado de este ecosistema presenta evidencias inconfundibles de deterioro, que obligan a mirar con suma atención lo que en el futuro cercano se decida $\mathrm{y}$ haga con los manglares ubicados en su jurisdicción. La Figura 6 muestra la superficie cubierta por ecosistema de manglar en el municipio Bajo Baudó.

El municipio de Bajo Baudó en su borde occidental, es prácticamente una línea recta, que presenta de sur a norte casi de manera ininterrumpida vegetación del ecosistema de manglar; esta vegetación se corta de manera abrupta en la desembocadura del río Baudó hacia el norte. Es decir, se presenta manglar en Cuevita, Virudó, Pavasa, Pilizá, El Tambito, San Miguel, Bella Vista, Sivirú, Guineal, Puerto Abadía, El Sepulcro y La Comba, entre otros.

Cerca de unas 3.150 hectáreas de manglares y natales se encuentran en buen estado de conservación, han sido poco intervenidos y presentan árboles que alcanzan hasta los 35 metros de altura; la vegetación con estas características representa tan sólo $13 \%$ del total de la superficie cubierta por ecosistema y se ubica bastante al oriente de la costa, los manglares cercanos al mar presentan preocupantes grados de alteración. Los sitios con el privilegio de tener manglares y natales conservados de manera adecuada se ubican en la quebrada Virice al norte del municipio, en cercanía a la desembocadura del río Pavasa, en los esteros El Chachajo, Brazo Largo, El Barrial, Potes, Luciano y Brazo Nuevo. Más de la mitad de la superficie total de manglar se encuentra medianamente intervenida, son más de 12.730 hectáreas las que presentan grados de intervención de hasta $40 \%$ de su área, dominando árboles cuya altura no va más allá de los 25 metros.

Las imágenes de satélite muestran cuatro grandes manchas de manglares con grado de intervención medio, la más importante se encuentra al norte del municipio y va desde y 


\section{Bioetnia Volumen 7 No 2 (julio-diciembre), 2010}

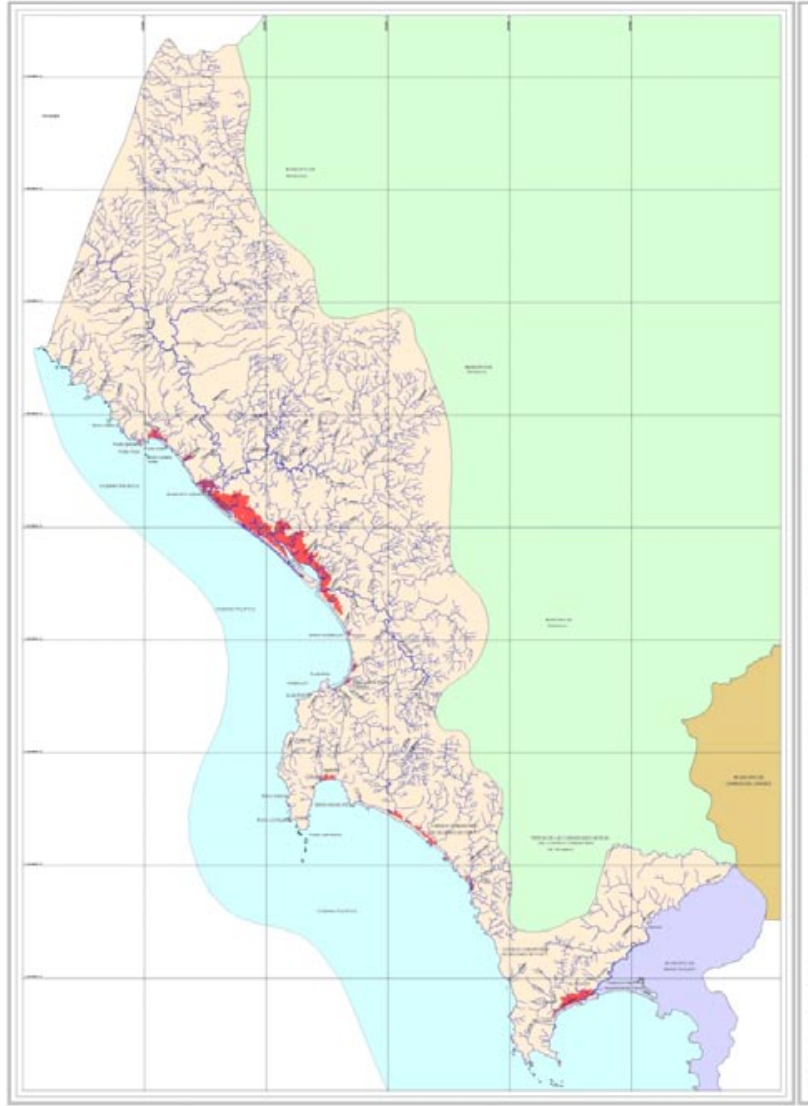

Figura 5. Unidades de cobertura del bosque de manglar
municipio de Juradó.

hasta los ríos Abaquia y Evari, pasando por Pavasa, Virudó y Cuevita; la segunda en importancia se encuentra al sur del municipio y pasa los caseríos Ijuá, El Firme, Los Rastrojos y Guineal. Una tercera mancha de manglares con mediano grado de intervención se encuentra al centro sur del municipio desde la ensenada de Docampadó hasta el río Usaraga y por último, una cuarta se encuentra en centro norte del municipio desde el sur del río Pilizá hasta el estero La Herradura.

La tercera parte de los manglares y natales del municipio del Bajo Baudó presentan altos niveles de intervención, es decir, se ha intervenido hasta un
$60 \%$ de su superficie, por lo que se destaca el predominio de árboles cuya altura se encuentra entre 5 y 12 metros. El área bajo niveles de intervención elevada es de 8039.8 hectáreas, que se concentran básicamente al sur y el norte del río Catripe, hasta llegar al río Puricha por el sur y hasta el río Abaquia por el norte, al oriente del Sivirú desde Puerto Escondido en el sur, hasta el río Baudó en el norte y a la margen izquierda aguas arriba del río Docampadó.

Los natales se encuentran mucho más conservados que los manglares propiamente dichos, mientras $84 \%$ de la superficie de natales presenta un bajo nivel de intervención o se encuentra poco intervenido, sólo un $7.6 \%$ de los manglares se encuentra en las mismas condiciones. En Tabla 5 se relacionan los datos más importantes del estado de los manglares y natales del municipio de Bajo Baudó.

\section{CONCLUSIONES}

En el año 1997, Sánchezy otros informaron la existencia de 64.750.4 hectáreas de manglares en el Pacífico chocoano, mientras que al año 2005, como fruto de este estudio sólo se informan 41.315.9 hectáreas. Lo anterior significa, que en nueve años transcurridos entre 1997 y 2005, el Pacífico chocoano sufrió una pérdida de $36 \%$ de su ecosistema de manglar, lo que equivale a la desaparición $2603.8 \mathrm{ha} /$ año, de continuar en una situación igual durante los próximos años, la región sólo contaría con bosques de manglar hasta el año 2021.

La mayor cobertura de manglares en la costa Pacífica chocoana se encuentra en los municipios del Bajo Baudó y Litoral del San Juan, entes territoriales que entre los dos

Tabla 5

Niveles de intervención de los manglares y natales en el municipio de Bajo Baudó

\begin{tabular}{|c|c|c|c|c|c|c|}
\hline \multirow[t]{2}{*}{ Grado de intervención } & \multicolumn{2}{|c|}{ Manglar } & \multicolumn{2}{|c|}{ Natal } & \multicolumn{2}{|c|}{ Manglar y Natal } \\
\hline & $\mathrm{Ha}$ & $\%$ & Ha & $\%$ & $\mathrm{Ha}$ & $\%$ \\
\hline Altamente intervenido & 7.761 .7 & 35.0 & 278.1 & 15.9 & 8.039 .8 & 33.6 \\
\hline Mediamente intervenido & 12.737 .7 & 57.4 & 0.0 & 0.0 & 12.737 .7 & 53.2 \\
\hline Poco intervenido & 1.677 .7 & 7.6 & 1.468 .2 & 84.1 & 3.145 .9 & 13.2 \\
\hline Total & 22.177 .1 & 100.0 & 1.746 .3 & 100.00 & 23.923 .4 & 100.0 \\
\hline
\end{tabular}


suman cerca de $85 \%$ de los manglares de la región, el restante $15 \%$ de los manglares del Pacífico chocoano se reparte entre los municipios de Juradó, Nuquí y Bahía Solano, en donde las coberturas de este ecosistemas no son grandes, pero revisten la mayor importancia para la población, porque de ellos derivan actividades económicas de relativa trascendencia para las municipalidades.

El estado de conservación de los natales de la costa Pacífica chocoana es bueno; cerca de $73 \%$ de la superficie cubierta por natales se encuentra en niveles de poca o baja intervención, muy a pesar de las excelentes propiedades físicas y mecánicas de la madera de esta especie. Estos datos generales contrastan con la situación de Bahía Solano, municipio en donde el $100 \%$ de sus natales (232.2 hectáreas) presenta altos niveles de intervención.

\section{LITERATURA CITADA}

Chapman, V.J. 1984. Botanical Surveys in Mangrove Communities. In: Snedaker y Snedaker (Eds.). The mangrove ecosystem: research methods. Bungay: UNESCO; p. 53-80.

Prahl, H. von, J. R. Cantera, R. Contreras. 1990. Manglares y hombres el Pacífico colombiano. Bogotá, DC: FEN/COLCIENCIAS; 193 p.

Sánchez-Paez H., Alvarez-León R. 1997. Diagnóstico y zonificación preliminar de los manglares del Caribe de Colombia. Bogotá, DC: Ministerio del Medio Ambiente, OIMT; 511 pp.

Sánchez-Paez, H. Ulloa-Delgado, G. A., Tavera-Escobar, H. V. 2004. Manejo integral de los manglares por comunidades locales, Caribe de Colombia. Proyecto Manejo sostenible y restauración de los manglares por comunidades locales del Caribe de Colombia. Bogotá, DC: Ministerio de Ambiente, Vivienda y Desarrollo Territorial, Corporación Nacional de Investigación y Fomento Forestal (CONIF), Organización Internacional de Maderas Tropicales (OIMT); $335 \mathrm{p}$

Villalba, J. C. 2008. Los manglares en el mundo y en Colombia: estudio descriptivo básico. Bogotá, DC: Sociedad Geográfica de Colombia, Academia de Ciencias Geográficas; 22 pp. En línea [fecha de acceso: 25 de mayo de 2008]. URL disponible en: http://www.sogeocol.edu.co

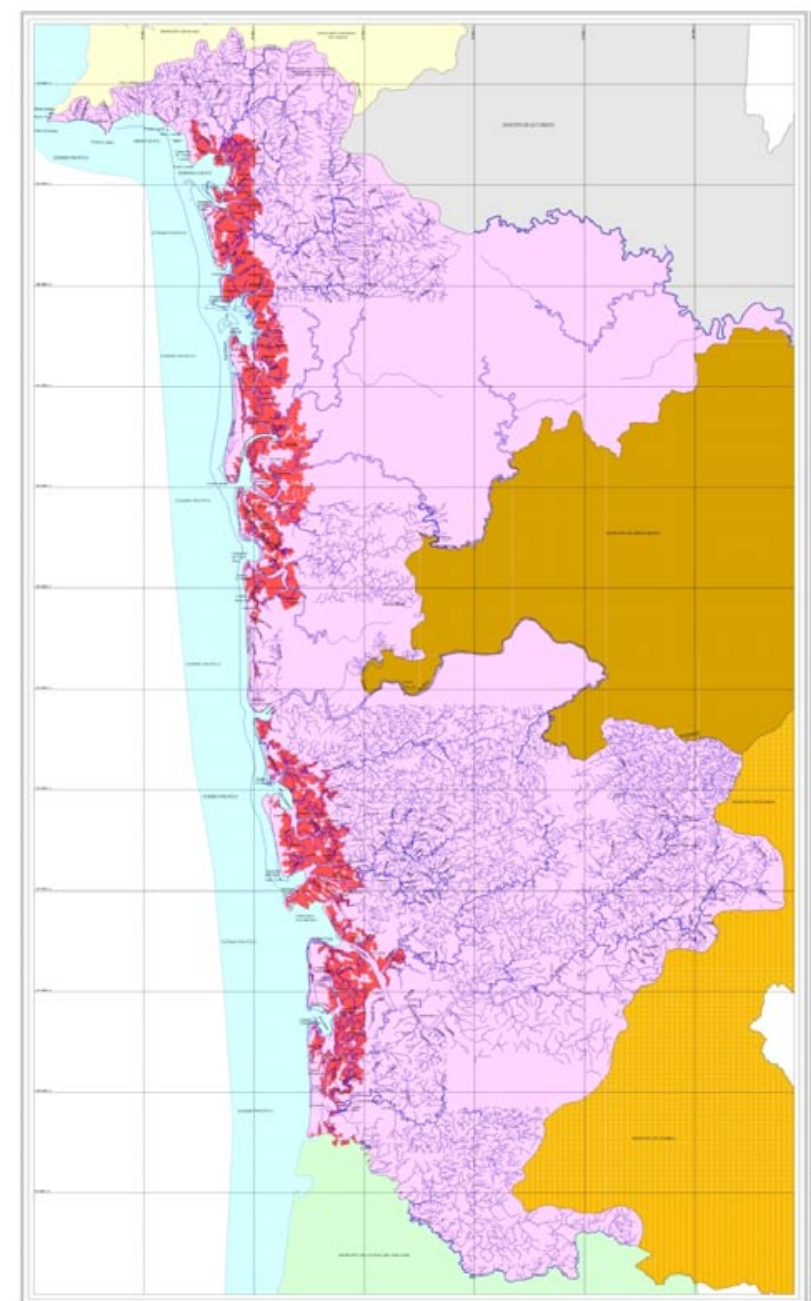

Figura 6. Unidades de cobertura del bosque de manglar, Bajo Baudó. 